\title{
Social and cultural dimensions of hypertension in Brazil: a review
}

\author{
Dimensões culturais e sociais \\ da hipertensão no Brasil: uma revisão
}

William W. Dressler 1

José Ernesto dos Santos 2

\footnotetext{
1 Department of Anthropology,

The University of Alabama. P. O. Box 870210, Tuscaloosa, Alabama, 35487-0210, USA. wdressle@tenhoor.as.ua.edu 2 Departamento de Clínica Médica, Faculdade de Medicina de Ribeirão Preto. Universidade de São Paulo. Av. Bandeirantes 3900 Ribeirão Preto, SP 14049-900, Brasil. jedsanto@fmrp.usp.br
}

\begin{abstract}
Elevated arterial blood pressure varies substantially in relation to social and cultural variables. Early work on acculturation, socioeconomic status, and blood pressure documented this variation, which could not be explained entirely by conventional factors such as diet, physical activity, or access to medical care. These findings stimulated the development of a model of stress and disease. The stress model emphasizes social and psychological factors that are perceived by individuals to be stressful, as well as factors that help individuals to respond to those stressors. Conventional stress models are, however, problematic because the primary emphasis is on individual perception, with little consideration of the social and cultural context in which stress occurs. This paper describes a complementary model of social and cultural influences on disease risk, placing greater emphasis on how individuals are able to approximate, in their own behaviors, shared cultural models of life, referred to as "cultural consonance". Findings from research in Brazil indicate that the higher an individual's cultural consonance, the lower his or her blood pressure. These results indicate the importance of linking different levels of analysis the cultural, the individual, and the biological - to understand disease risk.
\end{abstract}

Key words Hypertension; Blood Pressure; Culture

Resumo A prevalência de hipertensão arterial varia bastante em relação a fatores sociais e culturais. As pesquisas iniciais sobre aculturação, status sócio-econômico e pressão arterial documentam essa variação, que não pode ser explicada totalmente por fatores convencionais. Tais conclusões estimularam o desenvolvimento de um modelo de estresse e doença. O modelo de estresse enfatiza a participação de fatores sociais e psicológicos que os indivíduos percebem como estressores, e fatores que podem ajudar a responder a tais fatores. Os modelos convencionais de estresse são problemáticos porque sua ênfase primária é na percepção individual, com pouca consideração para o contexto social e cultural em que o estresse ocorre. Este artigo apresenta um modelo complementar de influências sociais e culturais sobre risco de doenças, dando maior ênfase a como os indivíduos são capazes de aproximar seus próprios comportamentos aos modelos culturais de vida que são compartilhados pela comunidade. Esse conceito é denominado consonância cultural. Pesquisas no Brasil sugerem que quanto maior a consonância cultural de um indivíduo, menor sua pressão arterial. Tais resultados também sugerem a importância de vincular níveis diferentes de análise no entendimento do risco de doenças.

Palavras-chave Hipertensão; Pressão Arterial; Cultura 
Mortality rates from coronary artery disease (CAD) vary substantially between nations throughout the world. CAD continues to be the leading cause of mortality in the nations of North America and Western Europe, despite a general decline in the magnitude of the rates. In countries undergoing economic development, including South American nations, CAD is the leading cause of death and mortality rates and tends to be rising (Dominguez et al., 1999). Essential hypertension, or elevated arterial blood pressure, is a major risk factor for CAD. Estimates of the prevalence of hypertension in South American countries vary widely, but the prevalence is certainly increasing (James et al., 1991). As Rose (1992) has shown, mean arterial blood pressure in a population is a strong predictor both of the rate of hypertension in the population and of the rate of CAD. Understanding the distribution of arterial blood pressure within populations is therefore fundamental to an understanding of the etiology of cardiovascular disease and to developing effective strategies of health promotion and disease prevention.

The factors that lead to (or reduce) high blood pressure have been investigated for several decades. Within populations in North America and Europe, increasing age and body mass are definite correlates of higher blood pressure, and there are significant sex differences within specific age groups. Sodium and alcohol intakes are strongly suspected as risk factors, at least for some populations and individuals. But these fail to explain a considerable degree of between-individual and between-population variation in blood pressure.

There are social patterns in the distribution both of blood pressure and of deaths from CAD. This has led to a considerable amount of research on social, cultural, and psychological variables as risk factors. The aim of this paper is to review research that has examined some of these processes in South America, and specifically in Brazil.

\section{Social patterns of cardiovascular disease}

Two major sets of observations have established the social patterns of cardiovascular disease. The first is the relationship between social and economic development and cardiovascular disease. As noted above, rates of CAD mortality are rising in the developing countries. Within that broad and disparate group of countries, CAD rates tend to be lower in those countries with a lower level of development (as measured by Gross National Product) and these rates tend to be higher in countries with a higher level of development (Dominguez et al., 1999).

This pattern of association between health and general economic development or social complexity can also be seen in a much broader anthropological classification of societies. The relative ease with which blood pressure can be measured has led to the accumulation of population blood pressure data from a diverse sample of societies around the world. Waldron et al. (1982) combined data on population mean blood pressures with data on the social and cultural characteristics of those populations derived from the Human Relations Area Files, a depository of social and cultural data from hundreds of societies around the world. The lowest population average blood pressures were observed among the technologically most simple societies, those relying on hunting and gathering, simple horticulture, or pastoralism for their subsistence economy. Population average blood pressures increased among societies based on sedentary agriculture, while the highest were among complex, industrialized societies. This association was independent of the population mean body mass index and the age and sex structures of the communities.

This study is a systematic evaluation of the hypothesis that the level of sociocultural complexity is associated with blood pressure (Henry \& Cassel, 1969). The implication of these findings is that cultural change that increases the contact between less complex and more complex societies leads to increases in blood pressure in the community undergoing change, a process known as "acculturation" or "modernization".

The acculturation or modernization hypothesis has been investigated in a number of societies around the world (Dressler, 1999). More highly acculturated or modernized communities are characterized by wage-labor versus subsistence economies; higher levels of formal education; use of national versus local languages; and a reduced emphasis on traditional patterns of social organization. A variety of studies in South America have examined modernization and cardiovascular disease, focusing especially on social change among tribal groups in the Amazon Basin. Isolated tribal groups tend to have extremely low average blood pressures ( $<110 / 70 \mathrm{~mm} \mathrm{Hg}$ ). Also, there is usually little or no increase in blood pressure with age (Carneiro \& Jardim, 1993; Pavan et al., 1999).

As communities are exposed to acculturative influences, these patterns change. For example, Silva \& Eckhardt (1994), Silva et al. 
(1995), and Mancilha-Carvalho et al. (1992) compared Indian communities in the north of Brazil differing in acculturation or modernization. Community average blood pressures were higher in the more modernized communities. Furthermore, these differences were independent of age and patterns of adiposity within and between communities.

In a few studies this pattern has not been observed (Fleming-Moran et al., 1991). Methodological problems, especially involving sample selection, can lead to non-comparable samples in communities differing in acculturation (Fleming-Moran \& Coimbra, 1990). But it is perhaps more important to remember that implicit in the acculturation hypothesis is a kind of ideal type of simple societies as existing in a pristine isolation from modernizing influences. Santos \& Coimbra (1998) show that the current condition of a community may not always be a good guide to its history of acculturation and hence to the long-term influences on morbidity.

The second major set of findings regarding the social patterns of cardiovascular disease involves the association of social inequality and health. In general, in North America and Europe there is an inverse association between various indicators of social class or socioeconomic status (such as occupational status, education, or income) and cardiovascular disease (including CAD mortality and blood pressure) (Adler et al., 1994). The same patterns have been observed in Brazil. Duncan et al. (1995) examined mortality rates for men in the state of São Paulo and found death rates in the lowest occupational class to be 3 to 4 times higher than rates in the highest occupational class, depending on how occupations were classified (and cardiovascular diseases were the principal cause of death). Ayres (1991), De Lolio et al. (1993), Cavalcante et al. (1995), Fuchs et al. (1994), and Martins et al. (1997) have all found mean blood pressure and the prevalence of hypertension to be higher among persons with lower occupational status, education, or income. These studies were conducted in different parts of Brazil, all in urban areas. Overall, the social class pattern of cardiovascular disease does not appear to be confounded with obesity, tobacco use, alcohol abuse, ethnicity, dietary risk factors, or access to medical care. And, as in other countries, there appears to be a continuous gradient of risk across economic status categories.

The associations of acculturation and socioeconomic status with cardiovascular health and disease clearly demonstrate the social patterns of disease. But, as Kasl has observed, these associations tend to be "opaque" (Kasl \& Wells, 1985). That is, both acculturation and socioeconomic status are static variables that give little insight into the processes by which social differences are translated into biological changes. Furthermore, this understanding of process is obscure on two levels of analysis. The first consists of the set of social and psychological processes that connect these social phenomena to the individual. The second consists of the set of psychological and physiological processes that result in disease. Both of these levels of analysis are in need of elaboration and point to the need for models of disease etiology incorporating social factors.

\section{Models of stress and cardiovascular disease}

The main inspiration for models of social influences on blood pressure came from the classic studies of stress and disease begun by Selye. Selye's work suggested that all organisms seek to maintain a physiologic and psychological homeostasis, or what psychophysiologists call a characteristic "level of arousal". There are environmental stimuli, large and small, that demand some kind of response from the organism. The organism responds in such a way as to restore the preferred level of arousal, if that is possible. This response involves linked psychophysiologic processes. Selye referred to this response, aimed at restoring homeostasis, as the General Adaptation Syndrome. If adaptive responses are appropriate, then homeostasis is restored; however, environmental stimuli (or "stressors") may be too great, or adaptive efforts may be inappropriate, and homeostasis will not be restored. This can then lead to a continuing adaptive load placed on the organism with a related drain of energy, physical and psychological, that could otherwise be devoted to growth or development. If this continued strain on the organism is sufficient, it can result in damage to the organism, damage that can be observed in the form of problems such as elevated arterial pressure - see Lipp (1996) for a review of Selye's ideas.

This stress model has been elaborated by social scientists who have examined the social and psychological factors that act as stressors, as well as the social and psychological factors that are resources in individuals' efforts to adapt to or cope with stressors. This has led to the definition of different kinds of stressors affecting individuals. These include psychological stressors such as feeling that circumstances 
in life are overwhelming and uncontrollable (Cohen et al., 1983); stressful life events, such as marital separation or death of a spouse, that are thought to be acutely stressful for individuals (Holmes \& Rahe, 1967); and chronic social stressors, or common and continuing problems individuals perceive in social roles in work and family life (Pearlin, 1982). The common theme linking these psychosocial stressors is the degree to which they would be perceived as threatening to individuals.

Two major resources for resisting stressors have been investigated. These are psychological coping styles and social supports. Coping styles refer to individuals' characteristic ways of dealing with stressors, such as seeking information, directly confronting the problem, or perhaps attempting to emotionally avoid the problem. Social supports refer to other people in the individuals' social network from whom they can seek advice and help in dealing with stressors. One of the most influential models of the stress process is the "buffering" model, in which higher access to social and psychological resources for coping with stress moderates the impact of those stressors and hence reduces the likelihood of adverse outcomes, while lower access to such resources can exacerbate the effects of stressors (Lazarus et al., 1985).

This general model of the stress process has been extremely useful in generating research. At the same time, it has left a number of questions unanswered. In the first place, it has not entirely explained socioeconomic differences in disease (Adler et al., 1994). After controlling for known risk factors and a variety of social and psychological variables, the inverse gradient between socioeconomic status and risk of disease persists. One reason for this may be that the stress model, as it is currently developed, does not take specific relevant sets of social factors into account.

In the second place, and closely related to the first question, the stress model as currently developed may place too much emphasis on the individual (McEwan \& Stellar, 1993) and not enough on how behavioral and psychological factors operate within a social and cultural context. Most research on the stress process has taken place with North American and European middle class samples. Given this cultural context, it is perhaps not too surprising that so much emphasis in these models is placed on individuals and their thoughts, feelings, and beliefs. In almost all stress models, what is or is not stressful is thought to be a function of what individuals perceive. This is consistent with the general Western European view of humans as distinct individuals who freely choose to engage in one or another form of behavior. Cultural context is unimportant because the individual is the ultimate arbiter of what is or is not real (Young, 1980).

On the one hand, this view of human behavior is appropriate because, in some sense, individuals do choose their behaviors, and an understanding of how inputs from the social environment are translated into organic disease requires that individual differences be studied. On the other, this perspective puts too much emphasis on individual thought and belief and not enough on how individual thoughts and beliefs are shaped by their cultural context. A concrete example may be helpful in making this point. As noted above, social support, which refers to the kinds of help or assistance received by individuals within their social network, has been found to be an important buffer against the effects of stressors. In most research on social support, virtually all emphasis is placed on the amount of support that an individual believes he has (measured as the number of persons from whom he believes he can obtain help) and on the specific kinds of assistance received (e.g. practical help or emotional support). But rarely is any attention given to who is providing that support. It is assumed that, as long as that support is there, then it is helpful.

But it may be that in certain social contexts, who is providing the support is as or more important than what support or how much support is being provided. Dressler et al. (1986) studied social support and blood pressure in a small town in the mountains of central Mexico. In a survey, respondents were asked to whom they could turn for help in response to a variety of common problems (e.g. needing a loan, problems in their work, and other similar problems). They were then asked if, for each problem, they could turn to a family member, a neighbor, a friend, or a compadre. The institution of compadrazgo was functioning in much the same way in this community as it had for hundreds of years. While the ostensive bond was between padrino and child, the compadre (or comadre) bond provided individuals with important links to others outside of their extended family. These links, cemented with the symbolic mortar of fictional kinship, are preferably made with others more successful and socially well placed than oneself. When the correlations between various kinds of social support and blood pressure were examined, the correlation between compadre support and blood pressure was the strongest $(r=-.39, p<.01$, for 
systolic blood pressure, adjusted for age and body mass), especially for men.

These and related results - reviewed by Dressler (1994) - strongly suggest that cultural definitions of preferred and appropriate social support must be taken into account in the relationship of social support and disease in addition to individual perceptions of the amount of support available. These results suggest that in specific cultural contexts, and in contradiction of the conventional individual difference model, not anyone can provide social support, but rather someone(s) must provide social support for it to be truly beneficial. And that "someone" is a person (or persons) culturally defined as important within the local system of social organization.

This perspective can be extended to the dimension of stressors. It has been recognized by many that what will be defined as stressful in any given setting will be a function of the culture of the group. Holmes \& Rahe (1967), for example, in their definition of the stressful life events emphasized that the specific events requiring social readjustment within any social group would be culturally defined. There is, however, some evidence to suggest that entire configurations of stressors related to health outcomes may be conditioned by the cultural context within which they occur, such that the actual effects of those stressors change. Dressler et al. (1995) found this to be the case in research on blood pressure in a community in Jamaica. They examined what until recently had been a relatively isolated community of peasant farmers. But over twenty years, that community was gradually engulfed by urban expansion. In effect, there were, side-by-side, two different varieties of Jamaican culture in the community, one rural and traditional, the other urban and modern. They found that different patterns of stressors were related to blood pressure for these two segments of the community, even though there were ostensibly in the "same" community.

These examples illustrate the point that a conventional model of stress and disease that places most or all of the emphasis on what individuals perceive to be stressful (or supportive) is too narrow. What is needed instead is a more complete model that links different levels of analysis: the cultural, the social, the psychological, and the biological. The development of such a model will enable research to move beyond the simplified formulations of stress and disease to a more comprehensive view of how human biological response is shaped by the social and cultural environment.

\section{Research on blood pressure in developing societies: a sociocultural model}

Over the past twenty-five years a sociocultural model of the stress process has been developed to understand the phenomenon of culture change and disease risk. A cognitive concept of culture has guided the development of this model. In this formulation, culture is not thought of as a group of people, or as some particular set of traits that clusters together in some social group. Rather, culture is defined as shared knowledge. Simply phrased, it is the knowledge that an individual must have in order to function appropriately as a member of a social group. The growth and development of a child is in large part a process of accumulating the varied kinds of knowledge necessary to function as a member of the group. Similarly, adult development consists in part of keeping pace with the changes in knowledge required by changing circumstances in the world. What makes this knowledge uniquely cultural is that it is shared, and, for the most part, it is implicit. For most people in a social system, cultural knowledge is rarely conscious knowledge; it is, rather, simply the way that the world works. Cultural knowledge guides what people do to subsist, it guides how they interact with others, and it guides what and how they believe. It is also useful to think of this knowledge as organized in schematic "cultural models" of the world (Strauss \& Quinn, 1997).

In formulating a sociocultural model of disease risk, emphasis was placed on understanding culture change in the context of economic development (Dressler, 1985). A major aspect of any social system is how social status or prestige gets allocated. In early work it became clear that higher status in many situations of development depended on the degree to which an individual could be successful in achieving the new lifestyles that accompanied modernization. Part of this modernization process involves individuals being drawn into the communication and media networks of the industrialized world. The lifestyles of the North American and European middle class are displayed prominently in these media. The term "lifestyle" refers to owning material goods (for example, owning houses, cars, appliances, and consumer electronics), as well as adopting related behaviors, such as going to the cinema, travel, and in general knowing about things. In the context of development, status is associated with achieving and maintaining this middle class lifestyle. It becomes, more generally, what the 19th century social theorist Thorstein Ve- 
blen referred to as a "common standard of decency". Phrased in terms of culture theory, the importance of this lifestyle came to be the new shared cultural model of status attainment.

This process is, however, complicated by slow change in the economic system of many developing societies. Access to the resources for achieving and maintaining this lifestyle usually depends on getting a better education and a better job. Usually, these kinds of opportunities expand at a much slower rate than peoples' aspirations for, and access to, a higher-status lifestyle. This means that at least some people will be trying to maintain a lifestyle that is inconsistent with their economic resources. In several studies, it was found that if individuals' rankings on a scale of lifestyle were higher than their rankings on a scale of economic resources, their blood pressure would be higher than if their lifestyle and economic resources were consistent. This was referred to as "lifestyle incongruity", and it seems to be a more-or-less constant concomitant of modernization and development.

But there are countervailing social forces. As noted earlier, within any social system there are support networks, people upon whom individuals rely for help or assistance during times of felt need. In traditional societies, where the ties of kinship tend to be more important than in industrialized societies, these support networks are concentrated in the family or kin network. Within that broad generalization, however, the specific configurations of culturally salient supports can take many forms. The example from Mexico has already been given. In the West Indies, support networks among households based on the presence of siblings are particularly important. In the African American community, a much broader range of extended family becomes the support network (Dressler, 1994).

This initial formulation of a sociocultural model of the stress process was tested in research in Ribeirão Preto, in the State of São Paulo in Brazil. Ribeirão Preto, like many Brazilian cities, has undergone explosive population growth since the 1950s. This demographic change has been accompanied by substantial economic growth in the areas of agriculture, manufacturing, health care, and financial services. Not surprisingly, the prosperity of the region has drawn substantial numbers of migrants from rural areas of the State, as well as from other parts of the country. And despite the strong economic growth, the social inequalities characteristic of Brazil as a whole are evident there. The favelas may not be so large or conditions of poverty as desperate as elsewhere, but they are there.

In initial research on the sociocultural model of stress, four populations groups were sampled: a favela; a group of stably employed farm workers; factory employees living in a housing project; and bank employees. A complicated design for gathering data was employed that involved four interviews with each respondent. The initial interview collected data on lifestyles and social supports; the second and third interviews consisted of 24-hour dietary recalls; and the fourth consisted of a clinical examination, including blood pressure measurement with a Dinamap and a fasting blood sample. The final sample with complete data consisted of 126 persons.

Lifestyle was measured with a 38-item scale that included major and minor material goods, as well as items referring to the consumption of information in the media. Economic status was measured with a ranking of occupational status developed in Brazil. It was found that lifestyle incongruity, measured as the degree to which an individual's ranking on lifestyle was greater than his ranking on occupation status, was associated with higher diastolic blood pressure, higher total cholesterol, lower high density lipoprotein cholesterol, and higher triglycerides. All of these associations were independent of age, sex, body mass, and dietary intake of cholesterol, fat, sodium, and potassium (Dressler et al., 1987, 1993; Dos Santos et al., 1994).

Social support was measured in much the same way as described for the study conducted in Mexico. Respondents were asked to whom they would turn for help for a series of common problems, including needing a loan, borrowing money, being ill, problems on the job, or feeling depressed. They were asked if they could seek support from a family member, a neighbor, a friend, or a compadre (The last relationship was included especially because of its potential importance as a source of support for rural migrants). Analyses of these scale items suggested that there were two basic dimensions embedded: kin support (family member) and non-kin support (all other supporters). Although it was anticipated that kin support would be much more important than nonkin support, both factors had a buffering effect on lifestyle incongruity in relation to blood pressure and serum lipids. For persons with low levels of support, there was a very strong association between lifestyle incongruity and cardiovascular disease risk factors. For persons with high levels of support, this association 
was much weaker, indicating a protective effect of support. And, these associations were independent of age, sex, body mass, and dietary intake (Dressler et al., 1993).

These results provided preliminary support for a model to explain social variation in blood pressure in Brazil. Furthermore, these results moved beyond conventional models of psychological stress by embedding the identification and measurement of variables in the context of social change and the culture of this local community. However, there are unanswered questions. For example, in the measurement of lifestyle incongruity, questions were not asked about a person's feelings of stress or deprivation. Rather, this was an objective measure of the discrepancy in a person's actual lifestyle and economic resources. It is unclear, therefore, how the association of lifestyle incongruity and blood pressure might be moderated by or even explained by the inclusion of, for example, perceived stress.

Another issue involves the basis for the selection and measurement of lifestyle and social support variables. These were chosen because they appeared to ethnographic observers to be culturally salient in this and in similar communities. It would be inappropriate to go into a long digression on the nature of anthropological inference here, but brief consideration of the process is relevant. For many years, anthropological researchers have placed emphasis on qualitative, ethnographic techniques of research and inference. These techniques, that involve long-term residence in a community and in-depth interviewing of a few key "informants," enable the ethnographer to gradually elicit and make explicit the everyday, takenfor-granted cultural knowledge that individuals share, but which they often find difficult to articulate. While these techniques are very useful in revealing cultural models, they also depend a great deal on the inferences made by the observer. As such, the inferences are of uncertain reliability. What is needed in anthropological research are methods that build upon the strengths of traditional ethnographic methods and that include more rigorous and reliable ways of testing ethnographic inference.

In recent years, a number of such techniques have been developed in cognitive anthropology, perhaps the most important being the cultural consensus model (Romney et al., 1986). The cultural consensus model enables the investigator to use a relatively small number of key informants to test for the degree of sharing of knowledge regarding some aspect of culture (referred to as a "domain"). If there is sufficient knowledge shared among informants, it becomes reasonable to infer that they are all drawing on essentially the same cultural model of that domain. The consensus model then enables the investigator to examine more rigorously the content of that cultural model. This technique was incorporated into a recent study of cardiovascular disease risk in Brazil, which will be described in the next section of this paper.

\section{Cultural consonance and blood pressure in Brazil}

The cultural consensus model provides the investigator two things. The first is an unambiguous criterion to determine if individuals and groups share sufficient knowledge about some cultural domain to reasonably infer they are drawing on the same cultural model. The second is an unambiguous profile of that knowledge based not on any single individual's knowledge, but on the aggregate knowledge of the group of informants, while giving higher weight to those informants more central in the information network.

What is needed, then, is some way of connecting that profile of cultural knowledge to the behavior of individuals. Dressler et al. (1996) developed the concept and measure of "cultural consonance" to describe this. Cultural consonance can be defined as the degree to which individuals, in their own behavior, approximate the shared cultural model of some phenomenon in their society. It was hypothesized that the more closely individuals are able to live in accordance with the cultural models of their society, the healthier they would be.

Research was again carried out in Ribeirão Preto. In this study, four neighborhoods were selected in the city that would represent the range of socioeconomic strata. These four neighborhoods included a favela (the poorest neighborhood), a conjunto habitacional (essentially a working-class housing project), a traditional middle-class neighborhood, and a new upper-middle-class neighborhood. In the first step of the research, five key informants from each neighborhood were selected. These informants were interviewed to provide data for cultural consensus analysis. Two domains were investigated, based on the previous research: lifestyle and social support. In the investigation of lifestyle, informants were asked to rate the importance of each of 39 lifestyle items, including material possessions and behaviors. They were asked to rate the items in 
terms of how important in general in the community each item was as signifying a person as a "success in life". The informants were asked to think in terms of the community, not in terms of their own individual beliefs or whether or not they owned the item. Each item was rated on a three-point scale (not at all important, somewhat important, very important).

For social support, the same set of problems and potential sources of social support described earlier was used. But cultural consensus analysis was used to test a somewhat more specific ethnographic hypothesis about the cultural domain of social support. In openended interviews, it seemed that respondents talked about seeking social support in a kind of stepwise manner, moving from the family outward to less intimate kinds of relationships. For consensus analysis, key informants from each neighborhood were asked to rank the different potential sources of support in response to each kind of problem, i. e., "Who would you turn to for support first? Who second? Who third?", and so on.

These two sets of data were then analyzed using the consensus model. The details of the technique are beyond the scope of this discussion - see Romney et al. (1986) for details. Briefly, what consensus analysis does is to treat the individual informants as if they were variables distributed across the ratings or rankings. Then, using a specific form of factor analysis, the degree to which the informants cluster together along a single continuum can be tested. If there is a sufficient clustering (according to a specific statistical criterion), one can infer that they share a single cultural model. Then, the responses of all the informants are weighted (by their degree of sharing of knowledge), and the aggregate profile of knowledge can be produced.

In this analysis, there was sufficient sharing of knowledge to infer that there were overall cultural models of lifestyle and social support among these informants. This is somewhat surprising given the wide range of economic status sampled, from the favela to the upper middle class. Nevertheless, consensus was achieved in both domains. The lifestyle model was interesting because it was quite different from what common sense would predict. The final model gave ratings of "somewhat important" or higher to 22 out of the 39 items. Furthermore, the highly rated items were not those of a lifestyle of "conspicuous consumption”, but rather described a kind of basic domestic comfort. In the favela, this was seen as a lifestyle that might possibly be attainable, al- though very few possessed it. In the higher economic strata, there was a tendency for people to speak of their material needs as not being all that important, when of course they easily possessed the basic lifestyle they described.

The consensus analysis clearly confirmed the stepwise basis for selecting sources of social support. For all but one problem, the pattern was first family, then friend, neighbor, and compadre. The pattern was altered only if the problem involved a person's job, when the pattern would be friend, family, neighbor, and then compadre.

The next step in the research was to connect these cultural models to the behavior of individuals. An epidemiological survey sample was selected from the four neighborhoods. Random samples within the neighborhoods were selected on the basis of household occupancy $(n=304)$. As in the previous study, four interviews were conducted with each respondent. The first interview collected sociocultural data. The second and third interviews were 24hour dietary recalls. The fourth interview was a clinical examination, including the measurement of blood pressure, adiposity (using bioelectric impedance analysis), and a fasting blood sample.

Measuring cultural consonance in each cultural domain involved a kind of pattern matching. In the sociocultural interview, all of the lifestyle items were included, and individuals were asked if they owned the item (for material goods) or to what degree they engaged in the specific behaviors (e.g. reading magazines). To measure cultural consonance in lifestyle, the items were dichotomized, and the number of the 22 items rated as important in the cultural model were summed, divided by 22 , and multiplied by 100 . This provided a coefficient that varied from 0 to 100 , where 0 meant no match to the profile of culturally important material goods in the cultural model, and 100 meant a $100 \%$ match to those material goods (the measure is normally distributed). For social support, individuals were asked to whom they would turn for support in those specific situations. Then, the profile of responses for each problem was matched to the cultural model. About $50 \%$ of the survey respondents answered all five of the social support questions in a way that matched the cultural model. About 25\% answered 4 of the 5 questions in a way that matched the cultural model. The remaining $25 \%$ answered 3 or fewer of the 5 questions in a way that matched the cultural model. These groups were designated "high, moderate, and low” cultural consonance in social support. 
Both higher cultural consonance in lifestyle and higher cultural consonance in social support were associated with lower blood pressure, after controlling for age, sex, body mass, conventional socioeconomic variables, perceived stress, and dietary intake (including sodium, potassium, dietary fat, and alcohol). The pattern of these associations is shown in Figure 1. The closer that persons approximate the normative cultural models of their own social group, the lower their blood pressure (Dressler, et al., 1997, 1998a, 1999).

As noted, the association of cultural consonance is independent of a measure of perceived stress. This was a measure developed by Cohen et al. (1983) and widely used in the United States. The emphasis in this measure is on the degree to which individuals feel they are not in control of events and circumstance in their lives. Although the measure is strongly correlated with cultural consonance in lifestyle $(r=-0.42$, $\mathrm{p}<0.01$ ) and less so with cultural consonance in social support ( $r=-0.17, p<0.03$ ), this psychological measure of stress does not mediate the relationship between cultural consonance and blood pressure.

There is, however, an interaction between cultural consonance in lifestyle and perceived stress in relation both to blood pressure and serum lipids. This interaction is shown in Figure 2 for blood pressure. Under conditions of low cultural consonance, increasing perceived stress is strongly associated with increasing systolic blood pressure. Under conditions of high cultural consonance, increasing perceived stress is not associated with blood pressure.

These results indicate that the more closely individuals are able to act upon the shared cultural models of their social group, the better their cardiovascular health.

\section{Discussion}

In this paper we have examined, in the context of Brazil, theory and research on social and cultural factors and cardiovascular disease risk. The earliest observations regarding social and cultural factors and disease risk documented the mean differences in blood pressure (and rates of related cardiovascular diseases) between societies with very different economic and social systems. Studies of isolated tribal groups showed conclusively that certain kinds of associations - most prominently that between age and blood pressure - that were thought to be "natural" based on research in North American and Europe were actually not.
Figure 1

Association between systolic blood pressure (adjusted for age, sex and body mass) and cultural consonance in lifestyle and cultural consonance in social support.

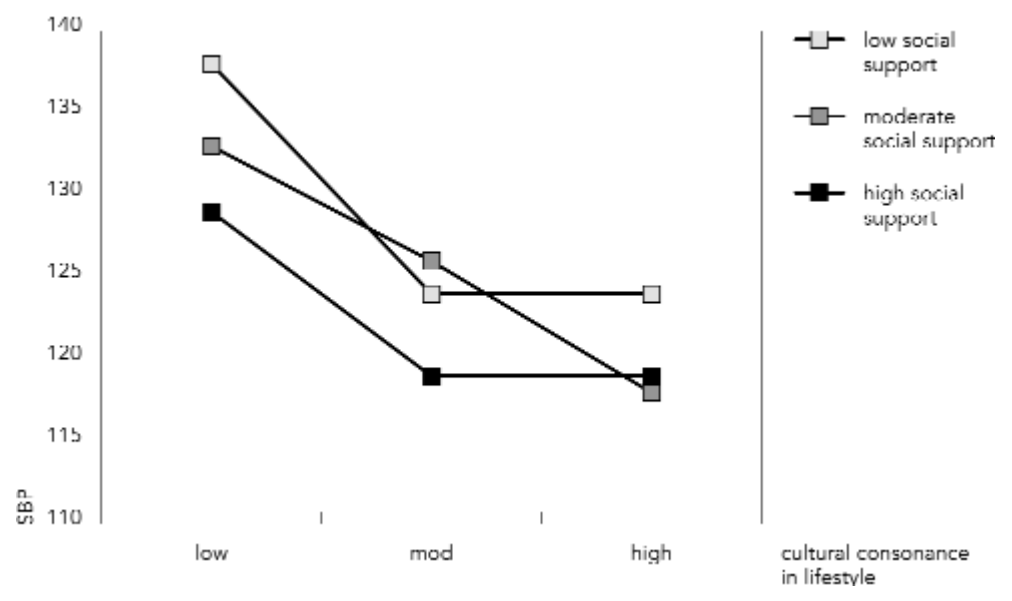

Figura 2

Association between systolic blood pressure (adjusted for age, sex, and body mass) and cultural consonance in lifestyle and perceived stress.

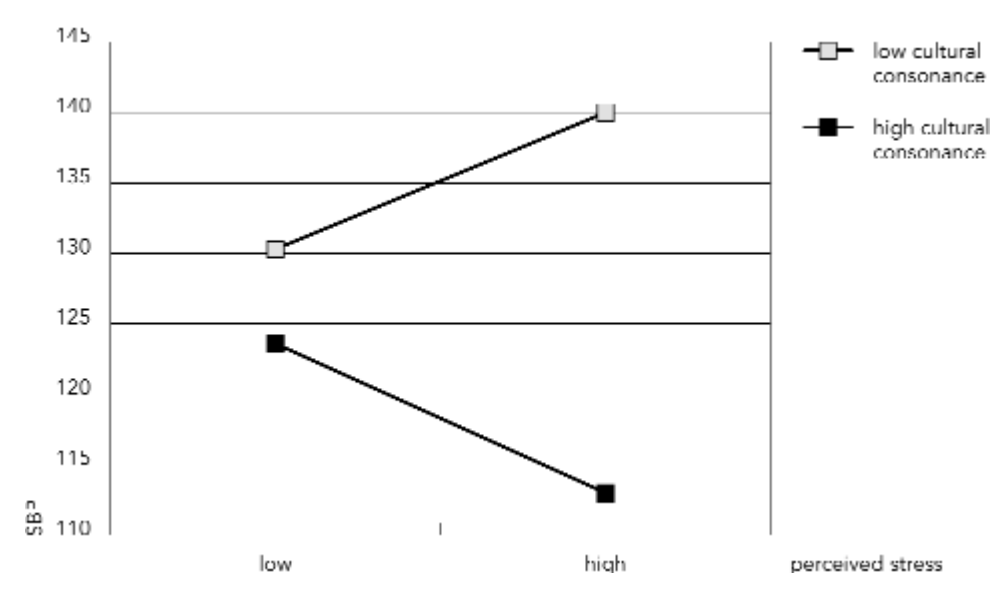


Rather, the associations of age and sex and blood pressure, and even adiposity and blood pressure, depended upon the type of society studied. Explanations for this phenomenon included the low levels of obesity, high activity levels, and low sodium intake observed in tribal societies, as well as the possibility that individuals who might develop high blood pressure at a later date had been selectively eliminated from the population by infectious or parasitic disease. Detailed studies showed, however, that these explanations could not account entirely for observed differences.

The association between societal type and blood pressure was further confirmed by the study of two kinds of social change: the migration of groups from more traditional to more modern communities, and social and cultural change occurring within a single community. Results of these studies show that, as social and cultural change occurs, mean blood pressure and rates of hypertension increase. Detailed studies show that changes in physical activity and diet accompany culture change, but these changes cannot account entirely for the magnitude of differences in mean blood pressures and rates of hypertension between groups.

Cassel et al. (1960) were among the first investigators to suggest that social and cultural processes might underlie these associations. Cassel acknowledged that changes in diet, physical activity, adiposity, and health habits such as smoking certainly were occurring in contexts of culture change. But, he argued, other fundamental changes were occurring. Individuals who had been socialized in one culture were confronting another. Literally, individuals who had been raised with one body of shared knowledge that guided their behavior and enabled them to understand and interpret others' behaviors were now in a situation in which they were attempting to negotiate a social world governed by a different set of meanings. This, Cassel argued, would lead to many situations of confusion and frustration in mundane social interaction, a situation likely to be stressful and, repeated over years, conducive to sustained disease.

This emphasis on the stressful nature of culture change led researchers to adopt the stress model developed in research in industrialized societies as their theoretical orientation, but with modifications introduced on the basis of ethnographic research in developing societies. So, for example, concepts like lifestyle incongruity were based on observations regarding the changing status value of lifestyles in developing societies. Similarly, in studying buffers against social stressors, researchers adapted existing concepts of social supports to knowledge of the importance of various kinds of social relationships in specific cultural contexts. These efforts can be seen as modifying somewhat the content of the stress model, but still working within that tradition.

The emphasis on the stress model for studying culture change and health was also consistent with socioepidemiological work on stress, which grew primarily out of the observations linking social class or socioeconomic status differences and health. With conventional factors (such as obesity or diet) unable to explain social class differences in health, researchers turned to the stress model.

More recent work on cultural consonance takes a different direction. Since the early and pioneering work of Cassel, with its central importance of culture as a system of knowledge and meaning, emphasis on culture per se has diminished in favor of the specification of (culturally relevant) biobehavioral processes. The results of studying cultural consonance, albeit tentative based on the results presented here from Brazil and a replication study in the United States (Dressler et al., 1998b), suggest that Cassel's original ideas may need to be reconsidered. The model of cultural consonance provides theory and method for understanding how individuals are distributed in cultural space, relative to prototypical shared cultural models of some domain of life. Cassel suggested that individuals could find themselves in a state of "cultural incongruity" because their own culture was not relevant in a particular context. Similarly, we are suggesting that individuals can be low in cultural consonance (or "culturally dissonant") because they are, for whatever reason, unable to act upon the widely shared ideas about how to live life appropriately. In either respect, individuals (or groups of individuals) are prevented from effective participation in their own society.

It would be straightforward to simply label this a stressful experience and leave it at that. There is, however, a growing body of laboratory research to suggest that the context of meaning surrounding social interaction can alter cardiovascular reactivity to that interaction. For example, Lynch (1985) found that transitory blood pressure elevations associated with social interaction can increase, and recovery to baseline lengthen, if the participants in the interaction are of unequal social status. Similarly, cardiovascular reactivity to laboratory social stimuli can be diminished by the presence of a supportive friend in the testing situation. 
These laboratory studies suggest that when social interaction is more orderly and meaningful, an individual's cardiovascular system maintains a more stable state. Individuals who attain and maintain a higher cultural consonance along several dimensions are living a life that is, by definition, more meaningful. Their lived experience of the world, not just in thought but in actual behavior, conforms to the widely shared ideas about (or cultural models of) the world. Individuals low in cultural consonance are literally not experiencing this stable and meaningful world. Instead, their lives are a constant reminder, in very concrete ways, of this instability and lack of meaning. It may be, then, that in response to mundane stimuli in the world, including social interaction, they are more highly reactive physiologically, a reactivity that in turn can lead to sustained changes in the vascular bed and higher blood pressure. This interpretation is not entirely speculative. A recent study from the West Indies has shown that males who do not conform to the local cultural ideal of male behavior have higher circulating levels of cortisol, and show greater reactivity in cortisol to mundane stimuli (Decker, in press).

The model of cultural consonance can also account for our earlier findings in Brazil. For example, careful examination of the measurement of lifestyle incongruity shows that people are not really trying to live a lifestyle of conspicuous consumption in the context of low income. Rather, a careful examination of this measure shows that it actually measures indi- viduals' difficulty in maintaining a very conventional lifestyle. Instead of living beyond their means, they do not have the means to maintain a very basic lifestyle. By isolating the elements of that lifestyle that are most highly culturally salient, the measure of cultural consonance in lifestyle simplifies the detection of that association. (This is analogous to isolating different fractions of serum lipids and observing the different effects of those fractions.) Similarly, the more careful assessment of cultural consonance in social support, based on the cultural model of social support, clarifies the basis for different kinds of supports having different effects on health.

This is not to say, however, that the model of cultural consonance can completely replace models of stress. As we have shown here, at least in our Brazilian sample, cultural consonance conditions or moderates the effects of perceived stress. Rather, what this review demonstrates is the importance of incorporating a cultural perspective into an understanding of psychological and behavioral influences on blood pressure. The concept of cultural consonance links the cultural level of analysis to individual behavior, and this dimension of behavior and its effects on health cannot be reduced to psychological or behavioral influences. Future research should examine in more detail how the linkage and interaction among cultural, social, and psychological factors influence cardiovascular disease risk, rather than concentrating on only one level of analysis.

\section{References}

ADLER, N. E.; BOYCE, W. T.; CHESNEY, M.; COHEN, S.; FOLKMAN, S.; KAHN, R. \& SYME, S. L., 1994. Socioeconomic status and health: The challenge of the gradient. American Psychologist, 49:15-24.

AYRES, J. E., 1991. Prevalência de hipertensão arterial em Piracicaba. Arquivos Brasileiros de Cardiologia, 57:33-36.

CARNEIRO, O. \& JARDIM, P. C., 1993. Pressão arterial em uma tribo Xavante. Arquivos Brasileiros de Cardiologia, 61:279-282.

CASSEL, J.; PATRICK, R. \& JENKINS, D., 1960. Epidemiological analysis of the health consequences of culture change. Annals of the New York Academy of Sciences, 84:938-949. 
CAVALCANTE, J. W. S.; DAZA, C. M.; PESSOA-CAVALCANTE, L.; PACHECO, W. S.; DE MENEZES, M. G.; MELO, R. \& GAMA, C. G., 1995. Prevalência e aspectos socioculturais e econômicos da hipertensão em um centro de saúde da área nordeste de Manaus. Arquivos Brasileiros de Cardiologia, 65: 493-496.

COHEN, S.; KARMACK, T. \& MERMELSTEIN, R., 1983. A global measure of perceived stress. Journal of Health and Social Behavior, 24:385-396.

DECKER, S., in press. Salivary cortisol and social status among Dominican men. Hormones and Behavior.

DE LOLIO, C. A.; PEREIRA, J. C.; LOTUFO, P. A. \& DE SOUZA, J. M., 1993. Hipertensão arterial e possíveis fatores de risco. Revista de Saúde Pública, 27:357-362.

DOMINGUEZ, L. J.; BARBAGALLO, M. \& SOWERS, J. R., 1999. Cardiovascular risk factors in South America and the Caribbean. Ethnicity and Disease, 9:468-478.

DOS SANTOS, J. E.; DRESSLER, W. W. \& VITERI, F. E. 1994. Fatores de risco de doença arterial coronariana e suas correlações com variáveis dietéticas e sociais. Arquivos Brasileiros de Cardiologia, 63: 371-375.

DRESSLER, W. W., 1985. Psychosomatic symptoms, stress, and modernization: A model. Culture, Medicine and Psychiatry, 9:257-286.

DRESSLER, W. W., 1994. Cross-cultural differences and social influences in social support and cardiovascular disease. In: Social Support and Cardiovascular Disease (S. A. Shumaker \& S. M. Czajkowski, eds.), pp. 167-192, New York: Plenum Publishing.

DRESSLER, W. W., 1999. Modernization, stress and blood pressure: New directions in research. $\mathrm{Hu}$ man Biology, 71:583-605.

DRESSLER, W. W.; BALIEIRO, M. C. \& DOS SANTOS, J. E., 1997. The cultural construction of social support in Brazil: Associations with health outcomes. Culture, Medicine and Psychiatry, 21:303-335.

DRESSLER, W. W.; BALIEIRO, M. C. \& DOS SANTOS, J. E., 1998a. Culture, socioeconomic status and physical and mental health in Brazil. Medical Anthropology Quarterly, 12:424-446.

DRESSLER, W. W.; BALIEIRO, M. C. \& DOS SANTOS, J. E., 1999. Culture, skin color, and arterial blood pressure in Brazil. American Journal of Human Biology, 11:49-59.

DRESSLER, W. W.; BINDON, J. R. \& NEGGERS, Y. R., 1998b. Culture, socioeconomic status, and coronary heart disease risk factors in an African American community. Journal of Behavioral Medicine, 21:527-544.

DRESSLER, W. W.; DOS SANTOS, J. E. \& BALIEIRO, M. C., 1996. Studying diversity and sharing in culture: An example of lifestyle in Brazil. Journal of Anthropological Research, 52: 331-353.

DRESSLER, W. W.; DOS SANTOS, J. E.; GALLAGHER Jr., P. N. \& VITERI, F. E., 1987. Arterial blood pressure and modernization in Brazil. American Anthropologist, 89:389-409.

DRESSLER, W. W.; DOS SANTOS, J. E. \& VITERI, F. E. 1993. Social and cultural influences in the risk of cardiovascular disease in urban Brazil. In: Urban
Health and Ecology in the Third World (L. M. Schell, M. T. Smith \& A. Bilsborough, eds.), pp. 1025, Cambridge: Cambridge University Press.

DRESSLER, W. W.; GRELL, G. A. C. \& VITERI, F. E., 1995. Intracultural diversity and the sociocultural correlates of blood pressure: A Jamaican example. Medical Anthropology Quarterly, 9:291313.

DRESSLER, W. W.; MATA, A.; CHAVEZ, A.; VITERI, F. E. \& GALLAGHER, P., 1986. Social support and arterial pressure in a central Mexican community. Psychosomatic Medicine, 48:338-350.

DUNCAN, B. B.; RUMEL, D.; ZELMANOWICZ, A.; MENGUE, S. S.; DOS SANTOS, S. \& DALMAZ, A., 1995. Social inequality and mortality in São Paulo State, Brazil. International Journal of Epidemiology, 24:359-365.

FLEMING-MORAN, M. \& COIMBRA Jr., C. E. A., 1990. Blood pressure studies among Amazonian native populations. Social Science and Medicine, 31:593601.

FLEMING-MORAN, M.; SANTOS, R. V. \& COIMBRA Jr., C. E. A., 1991. Blood pressure levels of the Surui and Zoro Indians of the Brazilian Amazon. Human Biology, 63:835-861.

FUCHS, F. D.; MOREIRA, L. B.; MORAES, R. S.; BREDEMEIER, M. \& CARDOZO, S. C., 1994. Prevalência de hipertensão arterial sistêmica associada a fatores de risco na área metropolitana de Porto Alegre. Arquivos Brasileiros de Cardiologia, 63: 473-479.

HENRY, J. P. \& CASSEL, J. C., 1969. Psychosocial factors in essential hypertension. American Journal of Epidemiology, 90:171-200.

HOLMES, T. N. \& RAHE, R. H., 1967. The social readjustment rating scale. Journal of Psychosomatic Research, 11:213-218.

JAMES, S.; ALMEIDA FILHO, N. \& KAUFMAN, J. S., 1991. Hypertension in Brazil: A review of the epidemiological evidence. Ethnicity and Disease, 1:91-98.

KASL, S. V. \& WELLS, J. A., 1985. Social support and health in the middle years. In: Social Support and Health (S. Cohen \& S. L. Syme, eds.), pp. 175-198, Orlando: Academic Press.

LAZARUS, R. S.; DeLONGIS, A.; FOLKMAN, S. \& GRUEN, R., 1985. Stress and adaptational outcomes. American Psychologist, 40:770-779.

LIPP, M. E. N., 1996. Stress: Conceitos básicos. In: Pesquisas sobre Stress no Brasil (M. E. N. Lipp, org.), pp. 17-34, Campinas: Papirus.

LYNCH, J., 1985. The Language of the Heart. New York: Basic Books.

MANCILHA-CARVALHO, J. J.; CARVALHO, J. V.; LIMA, J. A. \& SOUSA-E-SILVA, N. A.,1992. A ausência de fatores de risco para doença coronariana nos índios Yanomami e a influência da aculturação sobre a pressão arterial. Arquivos Brasileiros de Cardiologia, 59:275-283.

MARTINS, I. S.; MARUCCI, M. F. N.; VELAZQUEZ-MELENDEZ, G.; COELHO, L. T. \& CERVATO, A. M., 1997. Doenças cardiovasculares arterioscleróticas, dislipidemias, hipertensão, obesidade e diabetes melito em população da área metropolitana da região Sudeste do Brasil. III-Hipertensão. Revista de Saúde Pública, 31:466-471. 
McEWAN, B. S. \& STELLAR, E., 1993. Stress and the individual. Archives of Internal Medicine, 153: 2093-2101.

PAVAN, L.; CASIGLIA, E.; BRAGA, L. M. C.; WINNICKI, M.; PUATO, M.; PAULETTO, P. \& PESSINA, A. C., 1999. Effects of a traditional lifestyle on the cardiovascular risk profile. Journal of Hypertension, 17:749-756.

PEARLIN, L. I., 1982. The social contexts of stress. In: Handbook of Stress (L. Goldberger \& S. Breznitz, eds.), pp. 367-379, New York: Free Press.

ROMNEY, A. K.; WELLER, S. C. \& BATCHELDER, W. H., 1986. Culture as consensus: A theory of culture and informant accuracy. American Anthropologist, 88:313-338.

ROSE, G., 1992. The Strategy of Preventive Medicine. Oxford: Oxford University Press.

SANTOS, R. V. \& COIMBRA Jr., C. E. A., 1998. On the (un)natural history of the Tupi-Monde Indians. In: Building a New Biocultural Synthesis (A. H. Goodman \& T. L. Leatherman, eds.), pp. 269-294, Ann Arbor: University of Michigan Press.
SILVA, H. P.; CREWS, D. E. \& NEVES, W. A., 1995. Subsistence patterns and blood pressure variation in two rural caboclo communities of Marajó Island, Pará, Brazil. American Journal of Human Biology, 7:535-542.

SILVA, H. P. \& ECKHARDT, R. B., 1994. Westernization and blood pressure variation in four Amazonian populations. Collegium Antropologicum, 18:81-88.

STRAUSS, C. \& QUINN, N., 1997. A Cognitive Theory of Cultural Meaning. Cambridge: Cambridge University Press.

WALDRON, I.; NOWOTARSKI, M.; FREIMER, M.; HENRY, J. P.; POST, N. \& WITTEN, C., 1982. Crosscultural variation in blood pressure. Social Science and Medicine, 16:419-430.

YOUNG, A., 1980. The discourse on stress and the reproduction of conventional knowledge. Social Science and Medicine, 14B:133-146. 